\title{
Kinetic Modeling Study on the Emission Characteristics of an Axial- Fuel-Staged MILD Combustor
}

\author{
Xianglong Zheng \\ Institute of Engineering Thermophysics, \\ Chinese Academy of Science \\ University of Chinese Academy of Science \\ zhengxianglong@iet.cn \\ Beijing, China
}

\author{
Yan Xiong \\ Institute of Engineering Thermophysics, \\ Chinese Academy of Science \\ University of Chinese Academy of Science \\ xiongyan@iet.cn \\ Beijing, China
}

\author{
Fulin Lei \\ Institute of Engineering \\ Thermophysics, Chinese \\ Academy of Science \\ Beijing, China
}

\author{
Zhedian Zhang \\ Institute of Engineering \\ Thermophysics, Chinese \\ Academy of Science \\ Beijing, China
}

\author{
Yunhan Xiao \\ Institute of Engineering \\ Thermophysics, Chinese \\ Academy of Science \\ Beijing, China
}

\begin{abstract}
Axial-fuel-staged combustion is a promising technology that can be applied to lower emission, higher combustor outlet temperature, and extended operational flexibility of gas turbines. In this paper, two simplified chemical reactors network (CRN) models based on the staged combustion were established to investigate the emission characteristics of an axial-fuel-staged MILD (moderate or intense low-oxygen dilution) combustor. Firstly, an atmospheric experiment of a staged MILD combustor was performed to validate the CRN model. Results show that the experimental NOx emission trend is well captured by this CRN model and a NOx reduction of approximately $30 \%$ was also achieved by the staged combustion. Subsequently, based on the validated CRN model, a parametric study was conducted and the effects of fuel distribution, residence time, mixing characteristics in the secondary stage and heat losses were systematically analysed. The results show that the NOx emission can be reduced by more than $40 \%$ with an unaffected combustion efficiency by both increasing the ratio of secondary fuel and decreasing the ratio of secondary residence time. On the other hand, poor mixing in the secondary stage will significantly increase the thermal NO formation by $140 \%$ due to the local high temperature region. Finally, a non-adiabatic CRN model was studied and it was found that the heat loss would exaggerate the NOx-abatement potential of the axial-fuel-staged MILD combustor.
\end{abstract}

\section{INTRODUCTION}

With the development of turbine materials and cooling technologies, NOx regulations have been constraining factors to further increase the gas turbine efficiency [1]. On the one hand, by employing dry-low NOx (DLN) combustion to present gas turbines, NO formation through the two dominating pathways of thermal and prompt [2] can be effectively reduced due to the elimination of local high temperature regions. One the other hand, however, with the increase of the combustor outlet temperature (COT), thermal NO formation will be significantly accelerated because of its exponential temperature dependence [3]. For instance, once the temperature exceeds $1800 \mathrm{~K}$, the thermal $\mathrm{NO}$ reaction rate will double for every $35 \mathrm{~K}$ temperature rise [2]. Therefore, controlling the thermal NO formation at high temperature is crucial to the development of higher-parameter gas turbines.

Consequently, to reduce the NOx emission at higher COT and extend the operational flexibility, several original equipment manufacturers (OEMs) for gas turbine production including Alstom [4-6]、GE [7-9] and Siemens [10-12] have proposed different architectures of axial-fuel-staged combustors and applied them to their newly-designed gas turbines. The basic concept of axial-fuel-stage combustion is that by introducing an extra stream of fuel and air mixture of higher equivalence ratios near the combustor outlet, both the equivalence ratio of the upstream stage and the residence time of hot products in the highest temperature region can be reduced. Thus the thermal NO formation is reduced and the operational flexibility is extended due to a better combustion stability of secondary stage. Additionally, the equivalence ratios of the two stages should be carefully modulated to ensure the $\mathrm{CO}$ burnout efficiency at part-load conditions and minimize the NOx emissions in the whole operating conditions [9].

Apart from the conventional DLN combustion, MILD combustion [13], also known as flameless, HiTAC (High 
Temperature Air Combustion), CDC (Colourless Distributed Combustion), is another promising technology to reduce the pollutant formation of gas turbines. Recirculation of the burnt gas is a commonly-used approach to achieve MILD combustion [13]. In addition, axial-fuel-staged combustion is also proved to be another approach to achieve MILD combustion [14]. While in this paper, an axial-fuel-staged combustor consisting of a primary MILD combustor and a secondary jet in burnt gas is proposed and numerically studied.

Factors affecting the emissions characteristics of axialfuel-staged combustion includes: equivalence ratios of the two stages, distribution of the residence time, mixing between secondary injected mixture and the first burnt products and so on. Previous researches [15-17] with kinetic modelling approach concentrating on the factors mentioned above have been conducted, and a dramatic NOx-reduction potential of the axial-fuel-stage combustion has been observed. But the chemical reactors network (CRN) models in these research were idealized and none of them were validated with experimental data. Although Hoferichter et al. [18] constructed a validated CRN model for prediction of NOx formation in their staged model combustor, unfortunately, it was found that there was no NOx-reduction potential under prefect premixing conditions at atmospheric pressure [19]. Additionally, a quadratic dependence of NOx emission upon the fuel distribution has been presented in the experiment of GE 7HA combustion system [9]. Whereas there is still no such a quadratic dependence reported by the kinetic modelling investigations.

In this paper, a CRN model for an axial-fuel-staged MILD combustion was constructed firstly. And then a simple experiment based on the staged MILD combustor was performed to validate the CRN model. Subsequently, effects of fuel distribution, residence times, mixing in the secondary stage and heat loss on the emissions were systematically investigated with the validated $\mathrm{CRN}$ model.

\section{METHODOLOGY}

\section{CRN modelling of the staged MILD combustor}

Figure 1 shows a schematic drawing of the staged MILD combustor base on perfectly premixing assumption. Due to the dilution and strong mixing in MILD condition, simple models [13] even a single perfectly stirred reactor (PSR) [20] can be used to model the MILD combustor. Thus two sequential PSRs (PSR1 and PSR2) are used to model the first MILD combustion zone in the present study. PSR1 with a constant residence time of $1 \mathrm{~ms}$ [21] is used to mix and ignite the inlet fuel and air. PSR2 is used to simulate the MILD combustion zone in the first stage. PSR3 with a constant residence time of $1 \mathrm{~ms}$ is used to simulate the jet mixing and combustion of the secondary fuel and air. PFR2 is used to simulate the secondary post-flame region due to the weak gas recirculation near the combustor outlet. The residence time was calculated according to the following formula:

$$
\tau_{\text {PSR3 or PFR2 }}=\frac{\rho_{\text {gas }} V}{\dot{m}_{\text {fuel }}+\dot{m}_{\text {air }}}
$$

where $\mathrm{V}$ denotes the volume of the first or secondary stage, and $\rho_{\text {gas }}$ denotes the density of the burnt gas. $\dot{\mathrm{m}}_{\text {fuel }}$ and $\dot{\mathrm{m}}_{\text {air }}$ denote the total mass flow rate of the fuel and air entering the following reactors, respectively.For reference conditions, the residence times in PSR2 and PFR2 are $16 \mathrm{~ms}$ and $8 \mathrm{~ms}$, respectively. The calculation was performed using the commercial software package CHEMKIN-PRO, and a detailed chemistry mechanism GRI-Mech 3.0 [21] was used to model the combustion and pollutant formation.

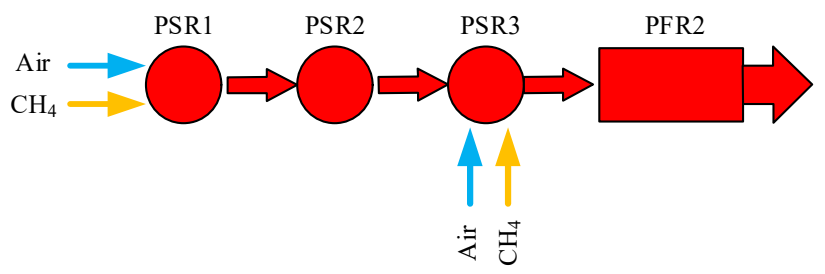

Figure 1. Schematic of perfectly-mixed staged MILD combustion model

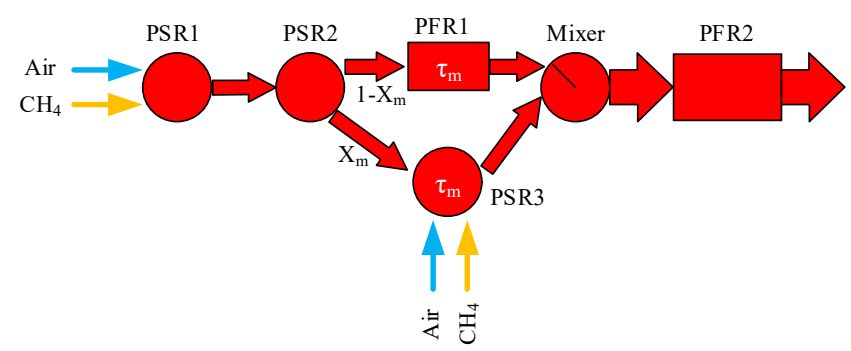

\section{Figure 2. Schematic of imperfectly-mixed staged MILD combustion model}

However, in practice, it is unrealistic to mix the secondary mixture with all of the burnt gas from the upstream stage in a very short time. Consequently, a local high temperature region will be formed by the imperfect mixing and the NOx formation may be increased through the thermal NO route [19]. Therefore, to take account of the effects of this imperfect mixing, an imperfectly-mixed staged MILD combustion model was constructed as shown in Figure 2. All configurations remain the same as the perfectly-mixed model, except that the previous PSR3 is substituted by a new PSR3 and PFR1. The burnt gas from the PSR2 is split into two streams. One with a proportion of $X_{m}$ is mixed with the secondary injected mixture in the PSR3 and another with a proportion of $\left(1-\mathrm{X}_{\mathrm{m}}\right)$ bypasses the PSR3 through the PFR1. The residence times of PFR 1 and PSR 3 are both $\tau_{\mathrm{m}}$. Then the gases from PFR1 and PSR3 are mixed in the Mixer and then enter PFR2. Two variables of $\mathrm{X}_{\mathrm{m}}$ and $\tau_{\mathrm{m}}$ are introduced in this imperfectly-mixed staged MILD combustion model and they are varied to modulate the mixing between the secondary injected mixture and burnt gases. As $\mathrm{X}_{\mathrm{m}}$ increases, or the $\tau_{\mathrm{m}}$ decreases, the mixing between the secondary injected mixture and burnt gas will be improved.

\section{Experiment setup}

To validate the above-mentioned imperfectly-mixed CRN model, a staged model combustor was constructed as 
shown in Figure 3. The experimental facility was operated in atmospheric conditions. The test facility was fuelled with pure $\mathrm{CH}_{4}$ (with a purity of $99.9 \%$ ) and the air was supplied with an air compressor unit. Both the temperatures of inlet fuel and air were measured to be $300 \mathrm{~K}$ with a K-type thermocouple. The bottom primary stage is a MILD burner constructed by Xiong et al. [22]. The burner consists of one central pilot nozzle and four premixed direct injection nozzles arranged circumferentially. Due to the high injection velocity of the four premixed nozzles, the burnt gas is entrained and recirculated, and then mixed with the fresh fuel and air. Thus the MILD condition can be achieved and a single PSR can be used to simulate this region in the CRN model. In the upper secondary burner, the fuel and air are mixed in the mixing tube firstly and then injected into the combustor through a round nozzle with an inner diameter of $6 \mathrm{~mm}$. Because of the high burnt gas temperature of the primary stage and low temperature rise (no more than $530 \mathrm{~K}$ based on an adiabatic flame temperature calculation) in the secondary stage, a MILD condition can be also achieved in the secondary stage.

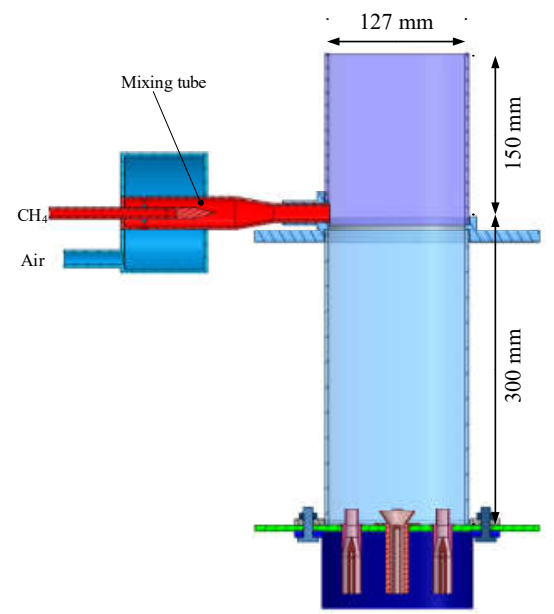

\section{Figure 3. Schematic drawing of staged MILD} combustor

The combustor was covered by two quartz tubes with an inner diameter of $127 \mathrm{~mm}$. A diverging transition section was placed above the combustor outlet to eliminate the nonuniform distribution of the exhausted gas species at the combustor outlet. A water-cooled gas probe was placed at the transition section outlet to sample the exhausted gas. Then the sampled exhausted gas was fed into a Testo ${ }^{\circledR} 350$ flue gas analyser. Several electrochemical sensors are used to analyse the contents of $\mathrm{NO}_{2}, \mathrm{CO}, \mathrm{NO}, \mathrm{O}_{2}$ and $\mathrm{CO}_{2}$. The uncertainty is $\pm 5 \%$ FS for $\mathrm{CO}, \mathrm{NO}$, and $\mathrm{NO}_{2}$, and $\pm 0.2 \% \mathrm{FS}$ for $\mathrm{O}_{2}$. The $\mathrm{CO}$ and $\mathrm{NO}$ measurements were corrected to $15 \% \mathrm{O}_{2}$ concentration for the convenience of the direct comparisons at different operating conditions.

The mass flow rates of the fuel and air were controlled and measured with four mass flow controllers (MFCs). The uncertainties of the MFCs are $\pm 1 \%$ FS for $\mathrm{CH}_{4}$ flow measurement and $\pm 1.5 \%$ FS for air flow measurement. A Labview program was used for the mass flow control and date acquisition. The flow rates, pressures and temperatures were recorded at a rate of $1 \mathrm{~Hz}$.

\section{RESULTS AND DISCUSSION}

\section{Validation of the CRN model}

To validate the CRN models, the experiment was performed under two different overall equivalence ratios $\left(\Phi_{t}\right)$. For each $\Phi_{\mathrm{t}}$, the air flow rate in each stage and the total fuel flow rate were held constant, while the fuel distribution was varied. Figure 4 plots the NOx emissions variance as a function of the secondary fuel fraction $\left(\mathrm{F}_{2}\right)$. Considering the heat loss of the combustor introducing a decrease of NOx emission [23] and the GRI-Mech 3.0 mechanism may overestimate NO formations under some circumstances [24], both of the experimental and calculated data were normalized by their NOx emissions at single stage mode (where the fuel flow rate of secondary stage is 0 ), respectively. Based on the experimental results, the NOx emission can be reduce by as much as $30 \%$ at $\Phi_{\mathrm{t}}=0.80$. A quadratic tendency is presented by the experimental data and well captured by the imperfectlymixed (denotes as "Mod-Imp") modelling results. In addition, as $\Phi_{\mathrm{t}}$ decreases, the NOx-reduction potential seems to be reduced and this trend is also captured by the imperfectlymixed CRN model. However, the perfectly-mixed model (denotes as "Mod-P") shows a monotonic decrease tendency and does not follow the experimental results.

Table 1. operating conditions for validation

\begin{tabular}{ccccccc}
\hline & \multirow{2}{*}{$\Phi$} & \multicolumn{2}{c}{$1^{\text {st }}$ stage flow rate (SLM) } & & \multicolumn{2}{c}{$2^{\text {nd }}$ stage flow rate (SLM) } \\
\cline { 3 - 4 } & & Air & Fuel & & Air & Fuel \\
\hline 1 & 0.80 & 628 & $49.0-37.4$ & & 15 & $0-8.2$ \\
2 & 0.75 & 628 & $46.0-36.0$ & & 15 & $0-7.7$ \\
\hline
\end{tabular}

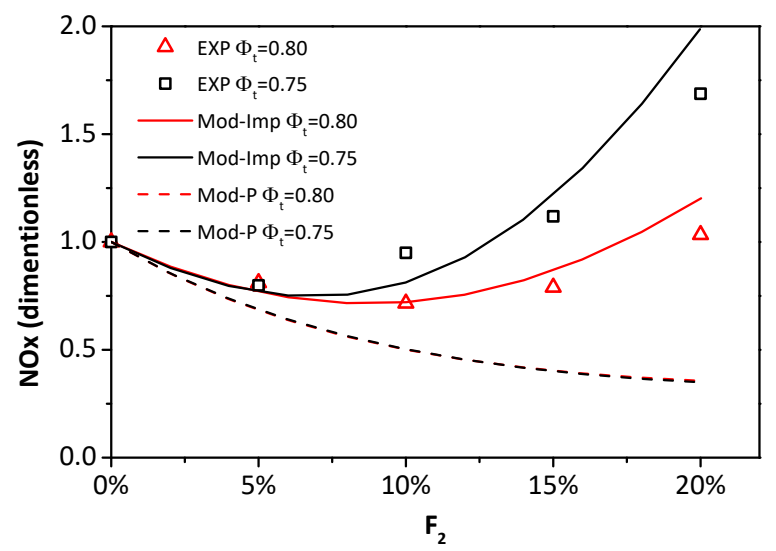

Figure 4. Comparison between the experimental data and the prediction of CRN model under two different overall equivalence ratios

\section{Effects of fuel distribution}

In the axial-fuel-staged combustor, the fuel distribution controls the temperature profile directly and affects the temperature-dependent NO formation. To investigate the fuel distribution effects on the emissions characteristics, the validated imperfectly-mixed CRN model was calculated with fixed residence times and varied fuel flow rates. The emissions as a function of combustor outlet temperature $\left(\mathrm{T}_{\text {out }}\right)$ under 
different secondary fuel fractions $\left(\mathrm{F}_{2}\right)$ are shown in Figure 5. With the increase of $\mathrm{T}_{\text {out }}$, both the $\mathrm{NOx}$ and $\mathrm{CO}$ emissions increase exponentially due to the increase of thermal $\mathrm{NO}$ formation and $\mathrm{CO}_{2}$ pyrolysis. For NOx emissions in Figure $5(\mathrm{a})$, when the $\mathrm{F}_{2}$ is increased from $0 \%$ (single stage) to $10 \%$, the NOx emission is shown to be reduced by more than $40 \%$. Whereas when the $\mathrm{F}_{2}$ is further increased to $20 \%$, the NOx emission is not further decreased but increased. This can be attributed to the increased temperature of PSR3 and this local high temperature region increases the NOx formation significantly as the increase of the secondary fuel produces an equivalence ratio close to 1 in the PSR3. However, for the perfectly mixed model, the increased NOx emission is not shown at $\mathrm{F}_{2}=20 \%$, because the local high temperature region cannot be simulated by this ideal CRN model.

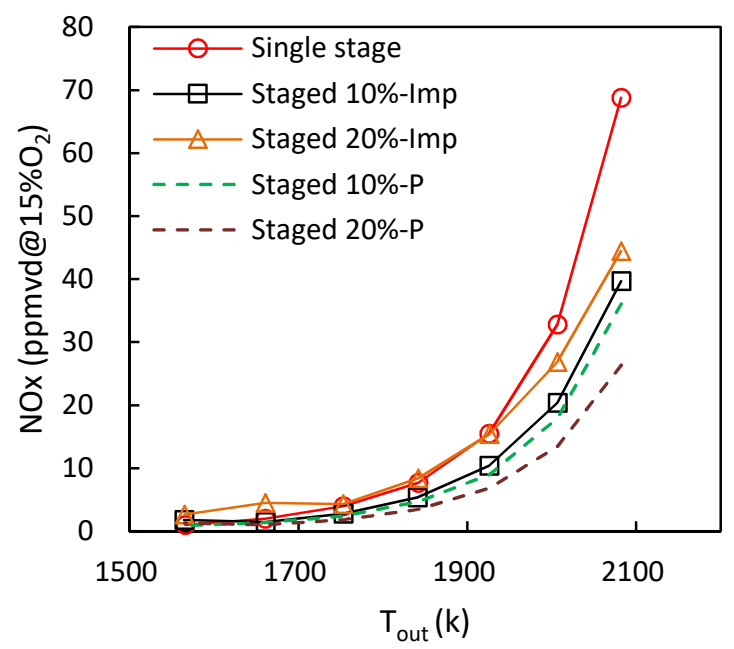

(a) NOx emission under different fuel distribution conditions

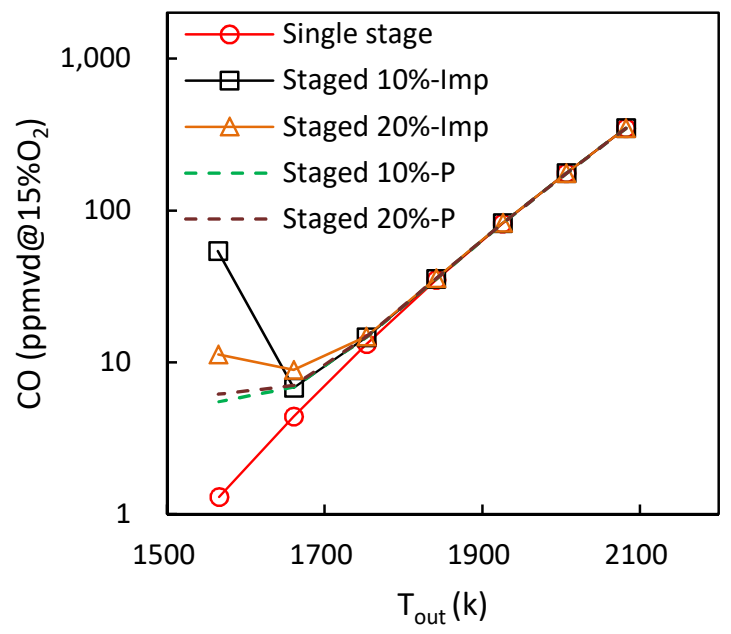

(b) $\mathrm{CO}$ emission under different fuel distribution conditions

\section{Figure 5. NOx and CO emissions varying with combustor outlet temperature under different fuel distribution conditions.}

In Figure 5(b), the $\mathrm{CO}$ emission is almost not affected when $\mathrm{T}_{\text {out }}$ is above $1800 \mathrm{~K}$. It means that although the first stage temperature is reduced by the increased $F_{2}$, it does not result in incomplete combustion when $\mathrm{T}_{\text {out }}$ is high. But when $\mathrm{T}_{\text {out }}$ is lower than $1800 \mathrm{~K}$, the $\mathrm{CO}$ emission could be significantly increased under the staged conditions. Therefore, it can be concluded that by using the axial-fuel-staged technology, NOx emission is able to be reduced without the decreased combustion efficiency at higher combustor outlet temperatures.

Figure 6 shows the NO formation through different pathways at $T_{\text {out }}=1925 \mathrm{~K}$. For the single stage combustion $\left(\mathrm{F}_{2}\right.$ $=0 \%$ ), the thermal $\mathrm{NO}$ formation accounts for the most part of the NOx emission. As $\mathrm{F}_{2}$ increases to $10 \%$, the NOx formation through the four pathways are all reduced. This can be attributed to the reduced first stage temperature, resulting in a global reduction of the reaction rates related to the NOx formation. Particularly, the thermal NO is the pathway affected by fuel distribution most effectively. As the $F_{2}$ is increased from $0 \%$ to $10 \%$, the reduction of the thermal-NO formation is nearly $35 \%$. However, as the $\mathrm{F}_{2}$ increases from $10 \%$ to $20 \%$, the NO formation through thermal, prompt and $\mathrm{N}_{2} \mathrm{O}$ pathways is increased significantly and the total NOx emission even exceeds the single stage mode. Considering that these three NO pathways are all temperature-dependent [25], the decrease of the NOx emission at lower $\mathrm{F}_{2}$ can be attributed to the decrease of the first stage temperature. Simultaneously, the temperature of PSR3 is also increased with the $F_{2}$, resulting in a local increase of the NOx formation in PSR3. Once the NOx increase in the PSR3 dominates over the NOx decrease in the first stage, the total NOx emission is increased.

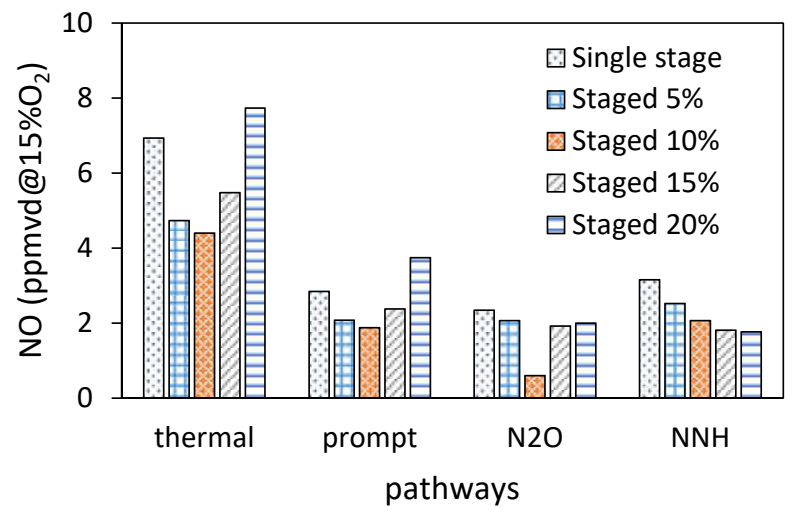

\section{Figure 6. NO formation through different NO pathways at $\mathrm{T}_{\text {out }}=1925 \mathrm{~K}$.}

\section{Effects of the residence time distribution}

For axial-fuel-staged combustion, the residence time distribution between the two stages depends on the injection position of the secondary fuel and affects the temperature profile alone the combustor axis. To study the effects of the residence time distribution on the NOx and $\mathrm{CO}$ emissions, the residence time in PSR2 and PFR2 are varied while the overall residence time and $\mathrm{F}_{2}$ is fixed at $26 \mathrm{~ms}$ and $10 \%$, respectively. Three residence time ratios between the first and secondary stage are studied and the results are shown in Figure 7.

As shown in Figure 7(a), with the decrease of the residence time in secondary stage, NOx emission is reduced 
and larger NOx reduction can be obtained at higher $\mathrm{T}_{\text {out }}$. This is because the shortening of the residence time in secondary stage acts primarily on the reduction of thermal NO formation, and the proportion of the thermal-NO formation is much higher at higher $T_{\text {out }}$. Thus the varying of the residence time distribution could have greater effect on the NOx emission at higher $\mathrm{T}_{\text {out. }}$ Figure 7(a) suggests that for the axial-fuel-staged combustion, NOx reduction can also be achieved by reducing the residence in the secondary stage, especially when $\mathrm{T}_{\text {out }}$ is higher than $1900 \mathrm{~K}$.

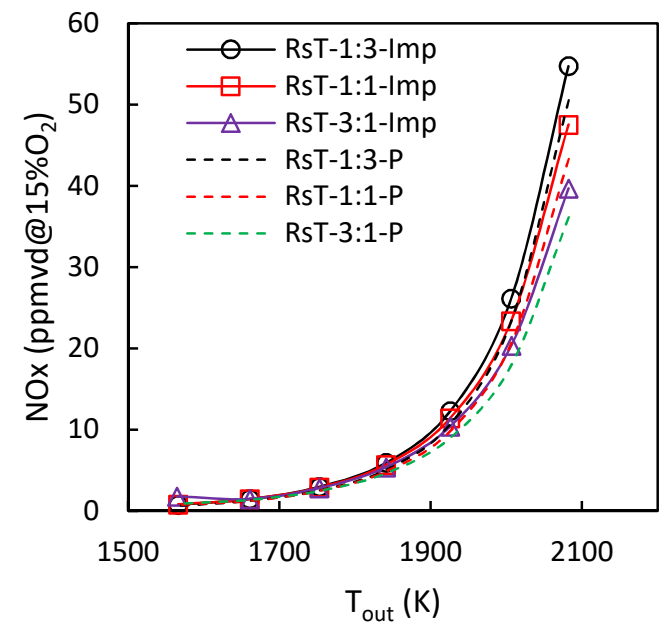

(a) NOx emission under different distribution of residence time

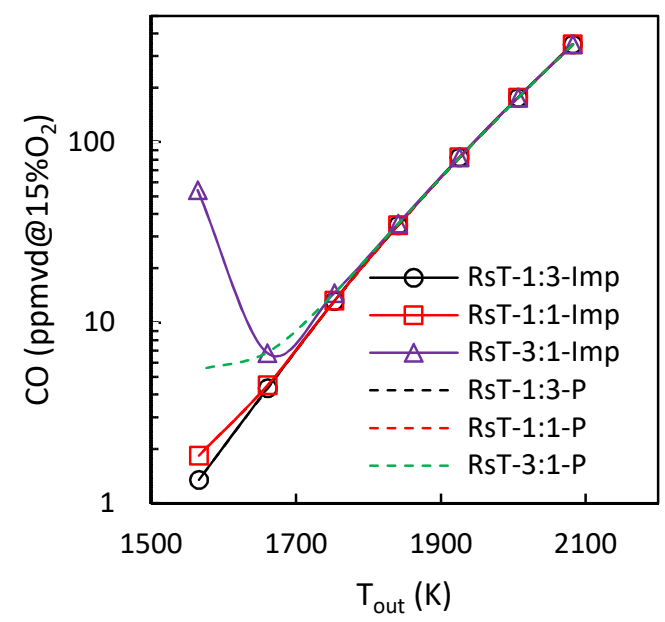

(b) $\mathrm{CO}$ emission under different distribution of residence time

\section{Figure 7. NOx and $\mathrm{CO}$ emissions varying with combustor outlet temperature under different distribution of residence times.}

Figure 7(b) shows that when $\mathrm{T}_{\text {out }}$ is lower than $1800 \mathrm{~K}$, the shortening of the residence time in secondary stage will lead to imperfect combustion and increased $\mathrm{CO}$ emission. However, as the $\mathrm{T}_{\text {out }}$ is above $1800 \mathrm{~K}$, the $\mathrm{CO}$ emission is almost not affected by residence time distribution. This can be attributed to the promoted oxidation rate in the secondary stage by the increased gas temperature from the first stage. Thus the burnout time of the secondary fuel is largely shortened and the $\mathrm{CO}$ emission is not increased. It suggests that for the design of the axial-fuel-staged combustor, the residence time in secondary stage should be minimized as much as possible by taking the advantage of the fast burnout of the secondary fuel. In this way, the benefits of NOx reduction could be maximized without any $\mathrm{CO}$ increase under high outlet temperature conditions.

\section{Effects of mixing between the burnt gas and jet mixture}

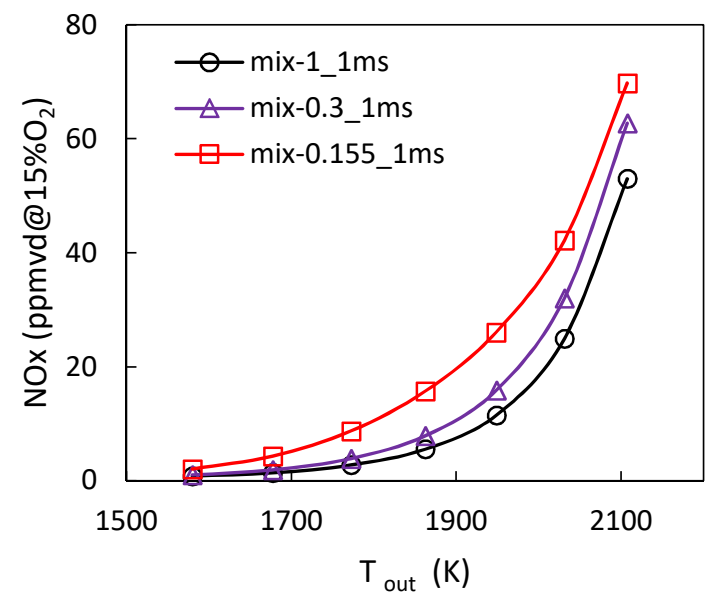

(a) NOx emission under different mixed burnt gas proportions of $\mathrm{X}_{\mathrm{m}}$.

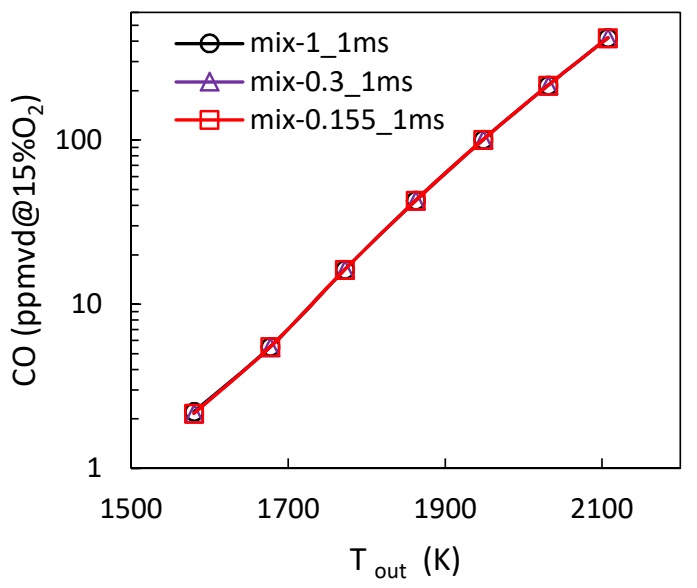

(b) $\mathrm{CO}$ emission under different mixed burnt gas proportions of $\mathrm{X}_{\mathrm{m}}$

\section{Figure 8. NOx and $\mathrm{CO}$ emissions varying with combustor outlet temperature under different mixed burnt gas proportions of $X_{\mathrm{m}}$.}

Considering the imperfect mixing between the burnt gas of the first stage and jet mixtures of the secondary stage in the practical axial-fuel-staged combustors, two abovementioned variables of $\mathrm{X}_{\mathrm{m}}$ and $\tau_{\mathrm{m}}$ are employed to adjust the mixing between the first and secondary stage while holding the ratios of residence times at $1: 1$ and $F_{2}$ at $10 \%$. Figure 8 shows the effects of $\mathrm{X}_{\mathrm{m}}$ upon the NOx and CO emissions when $\tau_{\mathrm{m}}$ is fixed at $1 \mathrm{~ms}$. The legend is noted in the form of mix-a_b, 
where the letter "a" denotes the proportion of the burnt gas mixed with jet mixtures $X_{m}$, and " $b$ " denotes the residence time of the gas in this locally imperfect mixing region $\tau_{\mathrm{m}}$. Therefore, the case of mix-1 $1 \mathrm{~ms}$ denotes the perfect mixing for all the burnt gas mixed with jet mixtures. On the contrary, the case of mix-0.155_1ms denotes the worst mixing for the burnt gas mixed with jet mixtures at stoichiometric conditions, forming the highest stoichiometric flame temperature in PSR3.

As shown in Figure 8(b), the CO emission is totally not affected by the change of $\mathrm{X}_{\mathrm{m}}$, which means that the imperfect mixing dose not lead to any incomplete combustion under this residence time distribution conditions. Contrastively, Figure 8(a) shows that with the decrease of $\mathrm{X}_{\mathrm{m}}$, the NOx emission is increased throughout the entire investigated $T_{\text {out }}$ range. Quantitatively, as the $\mathrm{X}_{\mathrm{m}}$ drops from 1 to 0.3 , the NOx emission is increased nearly $50 \%$ when $\mathrm{T}_{\text {out }}$ ranges from 1800 to $2100 \mathrm{~K}$. And when $\mathrm{X}_{\mathrm{m}}$ reaches the worst mixing condition, the NOx emission will be doubled or even tripled in the investigated $\mathrm{T}_{\text {out }}$ range. Therefore, despite of the neglected effects of $\mathrm{X}_{\mathrm{m}}$ on $\mathrm{CO}$ emission, the NOx emission seems to be very sensitive to the change of $X_{m}$. Sufficient burnt gas should be mixed with the secondary jet mixtures before the ignition in the axial-fuel-staged MILD combustor. Otherwise, the NOx emission might be rapidly increased and the benefits of this staged architecture would be eliminated.

Apart from the $\mathrm{X}_{\mathrm{m}}$, another variable of $\tau_{\mathrm{m}}$ is also investigated in Figure 9. As $\tau_{\mathrm{m}}$ increases from $1 \mathrm{~ms}$ to $3 \mathrm{~ms}$, the NOx emission is increased dependently. Particularly, larger $\tau_{\mathrm{m}}$ sensitivity can be observed at lower $\mathrm{X}_{\mathrm{m}}$ of 0.155 . However, the $\mathrm{CO}$ emission is only affected by the change of $\tau_{\mathrm{m}}$ when $\mathrm{T}_{\text {out }}$ is lower than approximately $1800 \mathrm{~K}$. In this $\mathrm{T}_{\text {out }}$ range, lower temperature of the first stage burnt gas leads to a lower oxidation rate in the secondary stage, thus the burnout time of the secondary fuel is extended and the $\mathrm{CO}$ emission at the combustor outlet is increased. While as the $\mathrm{T}_{\text {out }}$ exceeds $1800 \mathrm{~K}$, the oxidation rate in the secondary stage is increased and the CO formed in PSR3 is rapidly burnt out in the downstream PFR2. Thereby, the CO emission is not largely affected by the worsening of mixing conditions when $\mathrm{T}_{\text {out }}>1800 \mathrm{~K}$.

Additionally, an analysis of NO formation pathway under different mixing conditions is shown in Figure 10. Relatively, the NO formation is less affected through the $\mathrm{N}_{2} \mathrm{O}$, Prompt and $\mathrm{NNH}$ pathways, although the $\mathrm{NO}$ formation through $\mathrm{N}_{2} \mathrm{O}$ pathway is slightly increased with the worsening of mixing conditions and the NO formation through prompt pathway is slightly increased with the decrease of $\mathrm{X}_{\mathrm{m}}$. Apparently, the thermal NO formation dominates the overall NOx increase with the worsening of mixing conditions. With the decrease of $\mathrm{X}_{\mathrm{m}}$ and increase of $\tau_{\mathrm{m}}$, the thermal-NO formation is increased by approximately $140 \%$ from the case of mix $-1 \_1 \mathrm{~ms}$ to the case of mix $-0.3 \_3 \mathrm{~ms}$, so that the NO formation at staged mode even exceeds that of the single stage mode. This can be attribute to the combined effects of the increase temperature and residence time in the local partially-mixed region represented by PSR3 in Figure 2, which increase the NO formation in an exponential and linear way respectively.

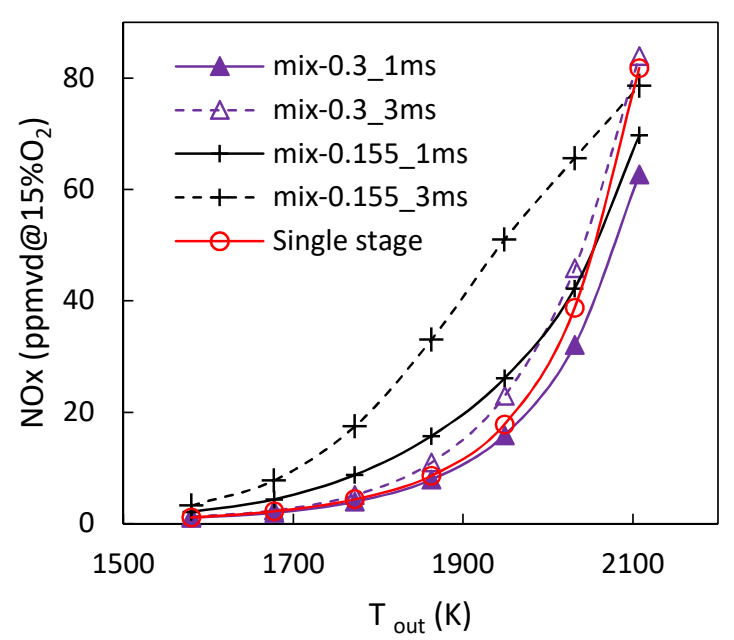

(a) NOx emission under different mixing time of $\tau_{\mathrm{m}}$.

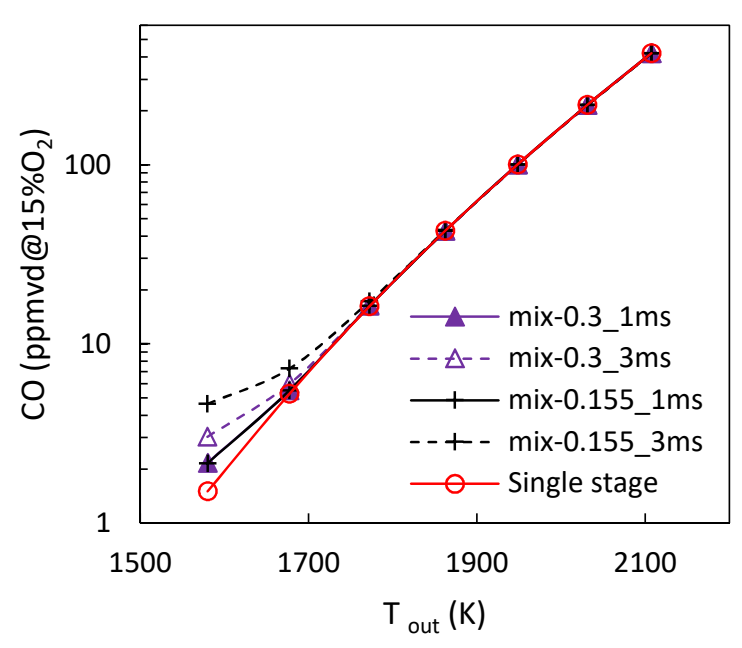

(b) $\mathrm{CO}$ emission under different mixing time of $\tau_{\mathrm{m}}$.

Figure 9. NOx and $\mathrm{CO}$ emissions varying with combustor outlet temperature under different mixing times of $\tau_{m}$ when $X_{m}=0.3$ and 0.155 .

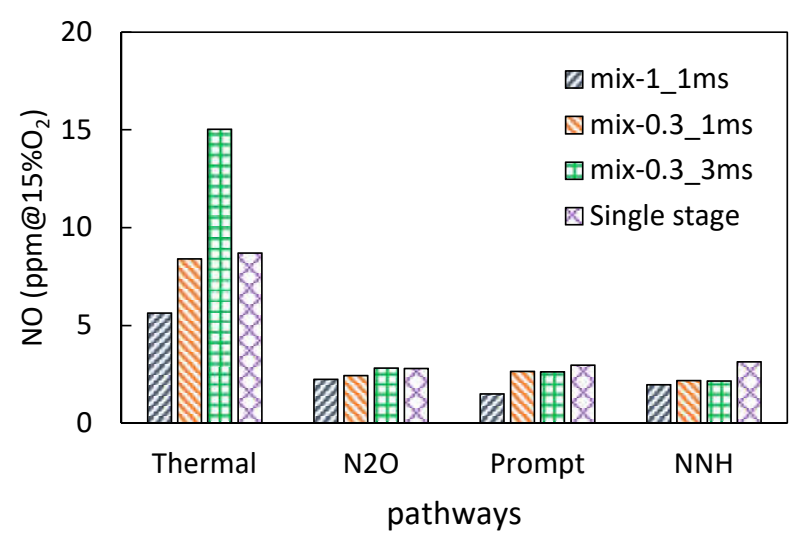

Figure 10. NO formation through different NO pathways at $T_{\text {out }}=1950 \mathrm{~K}$ under different mixing conditions. 


\section{Effects of the heat losses}

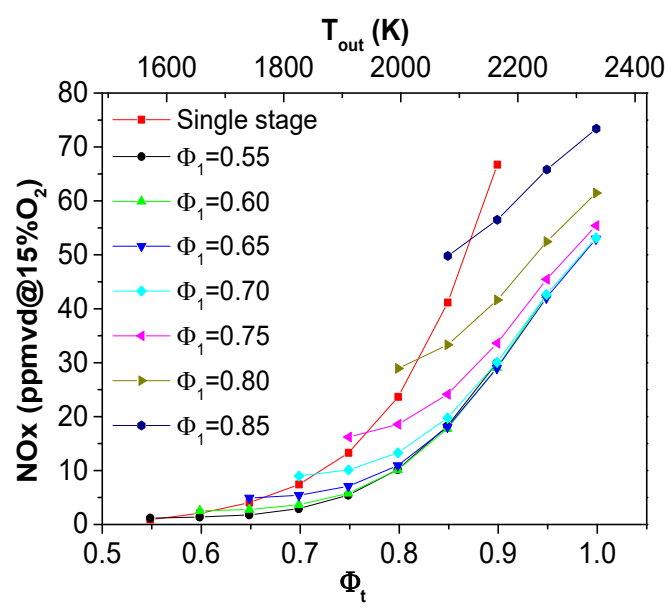

(a) NOx emission under adiabatic conditions.

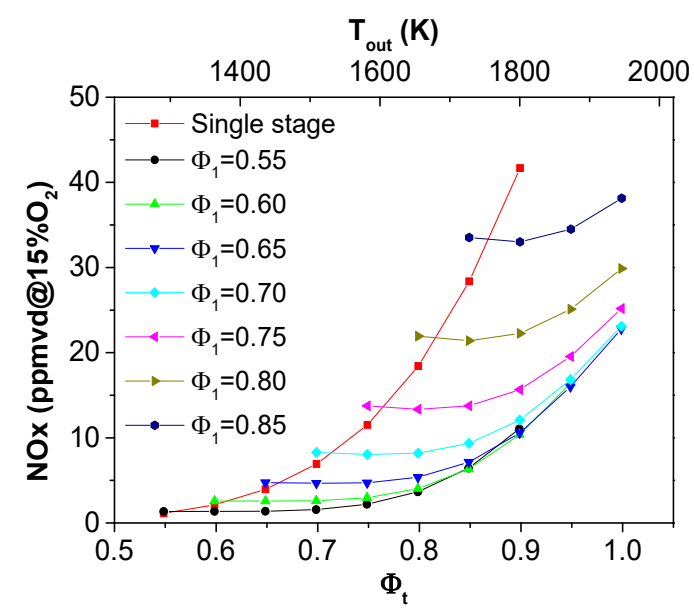

(b) NOx emission at the heat loss of $20 \%$.

\section{Figure 11. Comparison of the NOx emissions under adiabatic and non-adiabatic conditions.}

Although the combustors of industrial gas turbines are nearly adiabatic, the laboratory-scale test rigs of axial-fuelstaged combustor are usually non-adiabatic $[18,19,26]$. To study the similarities and differences between the results under adiabatic and non-adiabatic conditions, a heat loss of $20 \%$ was estimated with the measured combustor outlet temperature of our test rig and coupled in the CRN modelling. Figure 11 shows the comparison of the NOx emissions under adiabatic and non-adiabatic conditions. The red dot-noted curve denotes the NOx emissions at single-staged mode to show the benefits of staged combustion. While the other curves denote the staged mode at different first stage equivalence ratios $\left(\Phi_{1}\right)$. Obviously, the NOx-reduction benefits of axial-fuel-staged combustion are well presented in both Figure 11(a) and (b). In addition, at the same level of $\Phi_{t}$, lower $\Phi_{1}$ produces lower NOx emissions, which suggests that to minimize the NOx emissions of staged combustion, $\Phi_{1}$ should be decreased as much as possible (while the combustion stability and $\mathrm{CO}$ burnout should be maintained at the same time).

Under the non-adiabatic conditions (Figure 11(b)), the exponential increase of NOx emission with $\Phi_{\mathrm{t}}$ at single stage mode is similar to the adiabatic conditions, but with a global decrease of the NOx emissions due to the decrease of temperature. Moreover, for the staged combustion, the increase of NOx emission with $\Phi_{t}$ under adiabatic conditions is much sharper than that of non-adiabatic conditions. It means that a larger NOx-reduction potential might be presented under the non-adiabatic conditions. Therefore, conclusions from the non-adiabatic tests rigs should be drawn cautiously because the non-adiabatic test rigs tend to exaggerate the benefits of NOx-reduction when compared to the adiabatic combustion.

\section{CONCLUSIONS}

In this paper, two CRN models based on the axial-fuelstaged MILD combustion were constructed and validated with experimental results. Numerical studies on the effects of the fuel distribution, residence time distribution, partially mixing in secondary stage and heat losses were performed and conclusions can be drawn as follows:

(1) By increasing the proportion of secondary fuel to $10 \%$ at a constant $\mathrm{T}_{\text {out }}$, NOx emission can be reduced by more than $40 \%$ with few CO increase when $\mathrm{T}_{\text {out }}>1700 \mathrm{~K}$. However, further increase of the $\mathrm{F}_{2}$ would increase the NOx emission due to the imperfect mixing in the secondary stage.

(2) The shortening of the secondary residence time reduces the NOx emission effectively with few $\mathrm{CO}$ increase. Thus the residence time of secondary stage should be decreased as much as possible to minimize the NOx emission, but incomplete combustion should be avoided when $T_{\text {out }}$ $<1800 \mathrm{~K}$.

(3) With the worsening of the mixing condition in secondary stage (i.e. the decrease of $X_{m}$ and increase of $\tau_{m}$ ), the NOx emission is increased sharply mainly through thermal NO pathway due to the formation of local high temperature region. Also, the $\mathrm{CO}$ emission is potentially increased when the mixing time $\tau_{\mathrm{m}}$ is extended. Therefore, the mixing between the primarily burnt gas and secondary jet mixtures should be enhanced as much as possible in the design of the axial-fuelstaged combustor.

(4) Although similar NOx emission trends have been observed by the adiabatic and non-adiabatic calculations, exaggerated NOx-reduction benefits are also presented under non-adiabatic conditions. This suggests that conclusions should be deduced carefully from the non-adiabatic test rigs.

\section{NOMENCLATURE}

$\mathrm{CO}$ carbon monoxide

CRN chemical reactors network

$\mathrm{F}_{2} \quad$ secondary fuel fraction

MFC mass flow controller

MILD moderate or intense low-oxygen dilution

NOx nitric oxide

OEMs original equipment manufacturers

PFR plug flow reactor

PSR perfectly stirred reactor

$\mathrm{T}_{\text {out }} \quad$ combustor outlet temperature 
$\mathrm{X}_{\mathrm{m}}$

the proportion of the first stage burnt gas mixed with the secondary jet mixture

$\tau_{\mathrm{m}} \quad$ the residence time in PSR3

$\Phi_{\mathrm{t}} \quad$ overall equivalence ratios

\section{REFERENCES}

[1] Lieuwen, T., Chang, M., and Amato, A., 2013,

"Stationary gas turbine combustion: Technology needs and policy considerations," Combustion and Flame, 160(8), pp.

1311-1314.

[2] Tester, J. W., Drake, E. M., Driscoll, M. J., Golay, M. W., and Peters, W. A., 2012, Sustainable Energy: Choosing Among Options, The MIT Press.

[3] Moore, M. J., 1997, "Nox emission control in gas turbines for combined cycle gas turbine plant," Proceedings of the Institution of Mechanical Engineers Part A Journal of Power \& Energy, 211(211), pp. 43-52.

[4] Döbbeling, K., Hellat, J., and Koch, H., 2007, "25 Years of BBC/ABB/Alstom Lean Premix Combustion

Technologies," Journal of Engineering for Gas Turbines and Power, 129, pp. 2-13.

[5] Pennell, D. A., Bothien, M. R., Ciani, A., Granet, V., Singla, G., Thorpe, S., Wickstroem, A., Oumejjoud, K., and Yaquinto, M., 2017, "An Introduction to the Ansaldo GT36 Constant Pressure Sequential Combustor," ASMECharlotte, NC, USA, pp. GT2017-64790.

[6] Joos, F., Brunner, P., Schulte-Werning, B., Syed, K., and Eroglu, A., 1998, "Development of the sequential combustion system for the GT24/GT26 gas turbine family," Abb Review (4), pp. 4-16.

[7] Thomas, L. L., Simons, D. W., Popovic, P., Romoser, C. E., Vandale, D. D., and Citeno, J. V., 2011, "E-Class DLN Technology Advancements, DLN1+," ASMEVancouver, British Columbia, Canada, pp. GT2011-45944.

[8] Romoser, C. E., Harper, J., Wilson, M. B., Simons, D. W., Citeno, J. V., and Lal, M., "E-Class Late Fuel Staging Technology Delivers Flexibility Leap," Proc. ASMEVolume 4B: Combustion, Fuels and Emissions, pp. GT2016-57964.

[9] Karim, H., Natarajan, J., Narra, V., Cai, J., Rao, S., Kegley, J., and Citeno, J., "Staged Combustion System for Improved Emissions Operability and Flexibility for 7HA Class Heavy Duty Gas Turbine Engine” Proc. ASME, pp. GT2017-63998.

[10] Janus, B., Bigalk, J., Helmers, L., Witzel, B., Ghermay, Y., Huth, M., Johnson, C., Landry, K., and Sunshine, R.,

"Successfully Validated Combustion System Upgrade for the SGT5/6-8000H Gas Turbines: Technical Features and Test Results," Proc. ASMEVolume 3A: Coal, Biomass and Alternative Fuels; Cycle Innovations; Electric Power; Industrial and Cogeneration, pp. GT2014-27015.

[11] Gruschka, U., Janus, B., Meisl, J., Huth, M., and Wasif, S., "ULN System for the New SGT5-8000H Gas Turbine: Design and High Pressure Rig Test Results," Proc. ASME pp. GT2008-51208.

[12] Johnson, C., Pepperman, B., Koenig, M., Abou-Jaoude, K., and Anil Gulati, A. M., 2008, "Ultra Low NOx Combustion Technology," PowerGen InternationalOrlando, Florida.

[13] Perpignan, A. A. V., Gangoli Rao, A., and Roekaerts, D. J. E. M., 2018, "Flameless combustion and its potential towards gas turbines," Progress in Energy and Combustion Science, 69, pp. 28-62.

[14] Sidey, J., and Mastorakos, E., 2015, "Visualization of MILD combustion from jets in cross-flow," Proceedings of the Combustion Institute, 35(3), pp. 3537-3545.

[15] Qian, W., Zhu, M., and Li, S., 2017, "A Kinetics Study on the NOx Emissions of Axially Staged Combustion System for Gas Turbine Applications," Global Power and Propulsion ForumShanghai.

[16] Goh, E., Sirignano, M., Li, J., Nair, V., Emerson, B., Lieuwen, T., and Seitzman, J., 2019, "Prediction of minimum achievable NOx levels for fuel-staged combustors,"

Combustion and Flame, 200, pp. 276-285.

[17] Goh, E., Sirignano, M., Nair, V., Emerson, B., Lieuwen, T., and Seitzman, J., "Modeling of Minimum NOx in StagedCombustion Architectures at Elevated Temperatures" Proc. ASME, pp. GT2017-63787.

[18] Hoferichter, V., Ahrens, D., Kolb, M., and Sattelmayer, T., "A Reactor Model for the NOx Formation in a Reacting Jet in Hot Cross Flow Under Atmospheric and High Pressure Conditions," Proc. ASME, pp. GT2014-26711.

[19] Ahrens, D., Kolb, M., Hirsch, C., and Sattelmayer, T., 2016, "Influence of Pre-Flame and Post-Flame Mixing on NOx-Formation in a Reacting Premixed Jet in Hot Cross Flow," Journal of Engineering for Gas Turbines and Power, 138(8), pp. 1-10.

[20] Zhang, J., Mi, J., Li, P., Wang, F., and Dally, B. B., 2015, "Moderate or Intense Low-Oxygen Dilution Combustion of Methane Diluted by CO2 and N2," Energy Fuels, 29(7), pp. 4576-4585.

[21] Iyer, V., Haynes, J., May, P., Anand, A., 2005,

Evaluation of Emissions Performance of Existing

Combustion Technologies for Syngas Combustion, Proc.

ASME Turbo Expo 2005: Power for Land, Sea, and Air,

Reno-Tahoe, Nevada, USA, GT2005-68513.

10.1115/GT2005-68513.

[22] Frenklach, M., Bowman, T., and Smith, G., 2000, "GRI-

Mech," http://combustion.berkeley.edu/gri-mech/.

[23] Zhang, H., Zhang, Z., Xiong, Y., Liu, Y., and Xiao, Y.,

"Experimental and Numerical Investigations of MILD

Combustion in a Model Combustor Applied for Gas

Turbine," Proc. ASME, pp. GT2018-76253.

[24] Roa, M., Lamont, W. G., Meyer, S. E., and Lucht, R. P., "Emission Measurements and OH-PLIF of Reacting Hydrogen Jets in Vitiated Crossflow for Stationary Gas Turbines," Proc. ASME, pp. GT2012-68711.

[25] Cheong, K. P., Li, P. F., Wang, F. F., and Mi, J. C., 2017, "Emissions of NO and CO from counterflow combustion of CH4 under MILD and oxyfuel conditions," Energy, 124, pp. 652-664.

[26] Vaibhav, P., 2017, "Parametric Emission Prediction Model in Gas Turbines with Exhaust Gas Recirculation," Master, Delft University of Technology.

[27] Lamont, W. G., Roa, M., Meyer, S. E., and Lucht, R. P., 2012, "Emission Measurements and $\mathrm{CH}^{*}$

chemiluminescence of a Staged Combustion Rig for Stationary Gas Turbine Applications," Journal of Engineering for Gas Turbines and Power, 134, pp. 081502-081501081502-081507. 